\title{
Computer analysis of the electroencephalogram: Evoking, promoting, and provoking*
}

\author{
DONALD I. TEPAS $\dagger$ \\ Saint Louis University, St. Louis, Missouri 63103
}

\begin{abstract}
Having a long history of applying analog processing techniques to their data, electroencephalographers were among the first to use the digital computer in the laboratory. Methodological and terminological lessons learned from these applications are discussed in terms of their significance for the psychophysiologist in specific and the psychological laboratory in general.
\end{abstract}

Electrophysiologists have toyed with various forms of automatic data analysis for years. The use of analog filtering, integrators, and other elementary techniques by electroencephalographers was probably motivated to a considerable degree by the complex and frequently baffling nature of human brain waves. What is usually not apparent is the fact that many of these early efforts were fairly sophisticated and that some date back 35 years or more, e.g., the Grass and Gibbs (1938) report of Fourier transforms of the electroencephalogram (EEG).

One might also suggest that this interest in automatic data analysis was kindled by the difficulties often associated with the operation of early EEG equipment. Vacuum tube equipment limitations require the successful electroencephalographer to be either an amateur electrical engineer or to learn to communicate fairly well with an electrical technician. Learning a little about electrical practice frequently whetted the appetite of the investigator for more objective techniques with, hopefully, improved sensitivity and validity.

Despite this long history and interest in automatic data analysis, most contemporary use of the human EEG is an art form that involves visual examination or manual measurement with a ruler of polygraph recordings. The reliability and validity of these nonautomatic forms of EEG measurement is still open to question despite 40 some years of application. In both the clinic and

\footnotetext{
* This paper is the presidential address presented at the Third Annual Meeting of the National Conference on the Use of On-Line Computers in Psvchology. Research reported in this paper is supported in part by Grant MH 14020-03 from the National Institute of Mental Health, or by Contracts AF49(638)-1606 and AFo8(635)-3627 from the United States Air Force.

†Requests for reprints should be sent to Donald I. Tepas, Department of Psychology, Saint Louis University, 221 North Grand Boulevard, St. Louis, Missouri 63103.
}

psychological research, the human EEG most frequently plays the role of providing supportive evidence to confirm conclusions based on other dependent variables, rather than serving as a source for original and significant hypotheses.

The introduction of solid state electronic components and the subsequent availability of appropriate digital data processing technique and equipment for handling analog data has resulted in what might be termed a second-generation effort to apply automatic data analysis techniques to EEG data. The exploratory work of the M.I.T. Communications Biophysics Group (1959) as well as that of numerous unsung heroes, can be used as a benchmark. Plus or minus a year or two, I shall use 1959 to mark the start of a "second-generation" effort to apply automatic data processing techniques to EEG data. I term this a second-generation applications effort for a number of reasons. First, it mainly involves the digital processing of data, frequently in an on-line real-time manner, rather than an analog or hybrid measurement or manipulation for the automatic analysis of the EEG.

Second, in its full-blown manifestation, this new applications effort has involved the use of assembly-line produced fixed program or programmable solid state digital computer systems designed or modified for the specific purpose of handling electrophysiological data. This is in sharp contrast to first-generation devices which were frequently one-of-a-kind handcrafted contraptions. Thus, since around 1959, use has not been limited to a handful of investigators. Conservative but casually confirmed estimates of sales indicate that several different manufacturers have each had one or more years of gross sales of these systems which were in excess of one million dollars. This may be small in comparison to 
Table 1

Terms Used in the Literature With Reference to Efforts at the Automatic Analysis of the Electroencephalogram

\begin{tabular}{|c|c|}
\hline ALPHA AVERAGE & INTERRATED CHRONOGRAMS \\
\hline AMPLITUDE PROBABILITY DENSITY & INTEGRATED TOPOGRAMS \\
\hline ALTOMATIC FREQUENCY ANALYSIS & PERIOD-AMPLITUDE ANALYSIS \\
\hline AUTO-CORRELATION & PHASE DETECTION \\
\hline AUTO SPECTROGRAMS & PHASE LAG ANALYSIS \\
\hline AVERAGE EEC FREQUENCY & POWER SPECTRAL DENSITY \\
\hline COHERENCE ANALYSIS & PROBABILITY DENSITY ANALYSIS \\
\hline COSPECTROGRAMS & QUASPECTROCRAMS \\
\hline CROSS-CORRELATION & SPATL10-TEMPORAL MAPING \\
\hline CROSS-SPECTHOCRAMS & SPECTRAL ANALYSIS \\
\hline FOURIEK ANALYSIS & SYNCHRONOUS COMPONENT ANALYSIS \\
\hline FOURIER IRANSFORMATION & TIME-DOMAIN ANALYSIS \\
\hline FREQUENCY SPECTRUM ANALYSIS & TOPOSCOPIC ANALYSIS \\
\hline FREQLENCY/VOLTAGE RATIO ANALYSIS & T.ERO-CROSSING ANALYSIS \\
\hline AVERAGING & RESPONSE AVERAGING \\
\hline AVERAGING TECHNIQUE & SIGNAL_-AVERAGING \\
\hline COMPUTER AVERAGING & SIGNAL SUMMATION \\
\hline EEG-AVERAGING & SUMMATION \\
\hline
\end{tabular}

other markets, but this exceeds the total medical electronics sales of many well known firms prior to our benchmark.

Third, this advance was possible because of related developments in computer accessories. Given the analog nature of EEG potentials, the simple availability of digital central processors was not enough to assure this second-generation applications effort. The development of economical low level analog to digital convertors with adequate speed and reliability was required. Also, the development of quality FM magnetic tape recorders, capable of handling low frequency EEG signals was important because, for the first time, it allowed investigators to store easily EEG potentials and retrieve them economically for off-line computer analysis. This allowed the electroencephalographer to explore digital data analysis techniques before laboratory dedicated computers were common. It also allowed one to sample use of the techniques without making a significant investment in time or money. Unlike psychologists, electroencephalographers were not used to crunching numbers in digital batch processing centers. Many electroencephalographers, preconditioned by their comfort with electrical technology, were eager to adopt the new technologies, but displayed a prejudice favoring on-site data analysis. Others, sensitized by the failure of their previous efforts to use automatic analog technology, were hesitant to invest equipment funds into unproven digital or solid state items.

Finally, it is important to note the concurrent developments in EEG amplification and recording techniques which also help delineate this second-generation applications effort. The introduction of solid state technology to EEG amplifier design improved the quality and reliability of the EEG recording itself. This was aided by improvements in electrode design and increased competition within the medical electronics market. Data automation efforts were less restricted and more practical when factors such as drift, signal distortion, and other artifacts were minimized. Design improvements also incorporated features which made equipment interface easier. I do not mean to suggest that recording problems no longer exist, but it is quite appropriate to say that significant improvements have clearly occurred. To modify a phrase frequently used by computer buffs: better data in, better data out!

Using the 1959 M.I.T. activity as a benchmark for the start of this second-generation effort should in no way ignore the importance of prerequisite efforts by Dawson (1954), Walter and Shipton (1951), and others (Cobb, 1959). The work of these investigators is frequently overlooked since they used analog equipment and were not resident in the United States. In fact, many of the techniques which they championed were simply up-dated and popularized by American investigators. It should be obvious that the transition involved in going from first-generation applications to second-generation applications was gradual in nature, spreading over many years surrounding our benchmark.

Regardless of where we fix our starting point, it seems reasonable to suggest that sufficient time has passed to allow a preliminary assessment of the nature and form of this change. We can now examine some 15 years of research following the introduction of modern digital data processing techniques to electroencephalography. This effort should be helpful not only to the physiological psychologist, but also to those working in other areas of psychology. In fact, I don't think that there is any other area of research in the life sciences where on-line real-time digital data processing techniques have a longer history of use. Presumably, there are some generalizations from this history which may facilitate the introduction of on-line electronic data processing into other areas.

\section{SIMPLE METHOD OR SIMPLE MINDED?}

Table 1 is a partial list of terms used in the literature since 1959 with reference to various efforts at the automatic analysis of the EEG. Examination of this table reveals a major problem resulting from the influx of data processing methods into electroencephalography: confusion! In some cases, the terms refer to a device. Many of the devices are one of a kind as well as being poorly defined. Some are analog, some are hybrid, and others are digital. Frequently these 
differences are not evident. In other cases, the terms seem to refer to a form of data display or a data display device. In still other cases, the terms apply to mathematical techniques for treating the data. In numerous cases, different terms have been used to describe the same thing. Often one gets the impression in reading this literature that the authors themselves are not clear as to what operations have been performed on their data. Obfuscation is not rare.

Obviously, much of this confusion is related to journal editorial policies which severely limit methodological descriptions and/or do not require coherent specification of the dependent variable measures. Equipment designers and manufacturers frequently contribute to the problem by assigning unique labels to the functions or outputs of their equipment rather than making an effort to convey the more standard or common features of the processing. The development of methods and instrumentation journals, the organization of technical user groups, as well as efforts to develop industry-wide equipment standards, are all present day attempts to eliminate this and similar obfuscation. It is important to remember, however, that most of these corrective efforts are fairly recent happenings.

Someone might perform a useful service for EEG researchers and end some of the confusion by making a detailed examination of each of the terms in Table 1 in an attempt to identify and define differences and/or similarities. Frankly, I suspect that the sketchy nature of the methodological descriptions in the literature would make this a difficult, if not impossible, task. Avoiding such a complete expository approach, I have simply adopted a more pragmatic approach which is clearly tempered by the above factors. This analysis is an examination of what techniques are in fact being used with any degree of frequency by investigators. Prior to looking at the literature for some concrete figures, my biased impression was that research involving the so-called signal averaging method has gained considerable popularity in recent years while all other approaches to the automatic analysis of the EEG have had only modest use. The eight terms below the horizontal line in Table 1 all refer to this signal averaging technique and use much the same approach. In examining the literature, I simply asked what percentage of the published studies use the signal averaging technique in some form and compared it with the percentage of studies using all other approaches to automatic EEG analysis combined into one heterogeneous group.

Such an analysis of methods used is fairly time consuming since the use of automatic EEG analysis is frequently not evident in abstracts, title, or even methods sections. Thus, one must make a detailed examination of many papers on an individual basis. For this reason, my analysis was limited to selected volumes of one journal, Electroencephalography and Clinical Neurophysiology. Among neurophysiological

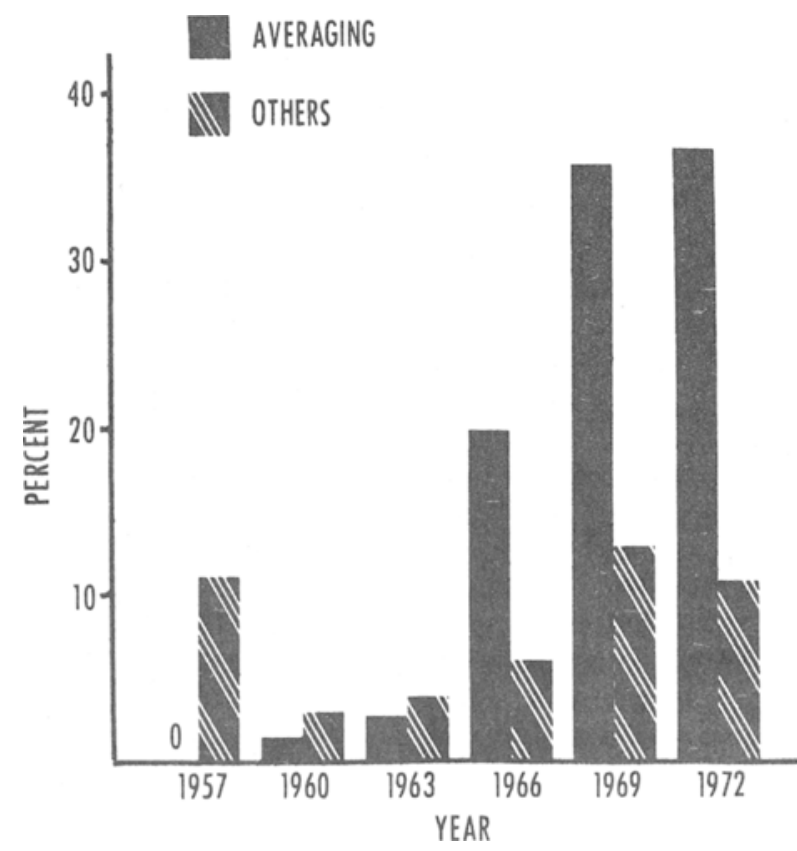

Fig. 1. Automatic electroencephalogram analysis as indicated by publications in the journal, Electroencephalography \& Clinical Neurophysiology.

publications, this journal reports on studies from an area much broader than its title would indicate. Both animal and human studies are found within its pages. Although the electrical activity of the human brain is a major theme, peripheral nervous system studies are welcomed by the editors. Dependent variables include a wide variety of electrophysiological measures ranging from gross scalp potentials to single unit recordings.

Main articles, clinical notes, and laboratory notes published in this journal every third year, starting with 1957, were examined, and the results of the analysis are presented in Fig. 1. Technical contributions, society proceedings, and journal supplements were not included in the results. For this analysis, no distinction was drawn between animal and human studies or between scalp and direct brain recordings. Assuming that our 1959 benchmark is an appropriate one and that our sample of the literature is reasonable, the data presented in Fig. 1 indicate that there have been some significant changes in what electrophysiologists are doing. In general, there has been a significant increase in the percentage of studies utilizing automatic data processing techniques to a point where over $45 \%$ of the reports examined involves some form of data processing. As I expected, the signal averaging technique is clearly the most frequently used technique in recent years. In 15 years, the use of the signal averaging technique has grown from minimal if at all to over one third of the papers published in this journal. I doubt that this is merely a result of an editorial change on the part of the journal. I propose that the data presented in Fig. 1 are a reasonable 
example of a real change in research methods and interests "introduced by advances in electronic data processing applications technology. Whether this has been a change for the good or not remains to be determined.

Given the complexity of EEG potentials, acceptance of electronic data processing techniques on such a wide scale in so short a time, relatively speaking, is perhaps not unexpected. The clear popularity of the signal averaging technique over all other forms of data analysis is also not difficult to understand. Just look at Table 1 again. "Averaging" or "summation" are not difficult mathematical terms to understand. The eight terms cited for describing signal averaging are not so dissimilar as to suggest that gross methodological differences are associated with these terminological differences. Once some initial and dramatic demonstrations of the technique were made, the average professional had little trouble acquiring a basic understanding of the signal averaging technique and grasping some insight into possible applications. It appears to be a simple minded technique which, to put it bluntly, any fool can use ... and many did. Most of the other terms in Table 1 appear to a naive reader to be hard to distinguish, unconventional in output, more difficult to understand, and most costly to implement.

Here, perhaps, is our first lesson to be learned. If you want to introduce electronic data processing techniques to a psychology laboratory, or any other laboratory previously untouched by modern laboratory data processing technology, pick a simple minded technique. Professionals are not merely afraid of computers. They are also afraid of techniques which they might have difficulty understanding and explaining to others. Some of them are so set in their ways that they will not even attempt to master any new technique which they cannot understand with minimal effort. The trick is to introduce a simple but fairly powerful technique which will seduce already committed established professionals into investing significant amounts of effort and funds in a new technology.

One serious problem which results from this, however, is that simple minded techniques can easily result in simple minded applications. Obviously an easy to understand fairly powerful technique does not guarantee appropriate applications. It may insure inappropriate applications. Given the resistance which many mature professionals give to the introduction of the computer (or any new methodology) into their laboratory-I suggest that this risk is one worth taking if it will get the conservative or insecure investigator to explore the wonderful world of laboratory electronic data processing.

The relatively rapid influx of signal averaging papers into Electroencephalography and Neurophysiology has no parallel in the traditional psychological journals. One might suggest that this is simply true because electroencephalographers have more simple minded colleagues than do psychologists. This may be true, but I seriously doubt that it is an appropriate explanation. To date, signal averaging has been fairly expensive and of ten beyond the budgets of many departments of psychology. Analog to digital conversion has been expensive both in terms of capital outlay and time sharing capacity. Departments add on-line electronic data processing capability but frequently do not include analog to digital capacity because of these costs. Dropping market prices will probably minimize this problem. Perhaps a more cogent explanation is simply related to the general prejudice of many traditional psychology journals in the past with regard to electrophysiological data in general and human EEG data in specific. In any case, one should not conclude that there has been little interest in relating psychological variables to EEG signal averaging data. There has been a fairly large effort to relate psychological variables to EEG signal averaging data.

Table 2 provides a partial listing of psychological terms or variables related in the literature to EEG signal averaging data. This table is simply an expansion of one previously published by Sutton (1969). I have added a few more recent developments as well as a few favorites of my own. I would not consider this table to be exhaustive. Few psychologists could examine this table without finding at least one term relating to their own personal research interests. I would not wish to suggest that each of the terms listed in Table 2 has a genuine relation to EEG signal averaging data, but I would suggest that a professional can be found to support each one.

The significance of EEG signal averaging data to psychology and psychologists has many philosophical, theoretical, and semantic dimensions which Sutton (1969), Uttal (1965, 1967), and others (Donchin \& Sutton, 1970; Clark, Butler, \& Rosner, 1970) have discussed. Rather than get embroiled in some of these fairly unsolvable issues, the remainder of this paper will be dedicated to a few rather practical methodological and terminological problems which have evolved from EEG signal averaging research. Hopefully, this discussion will benefit EEG research in specific and the psychological laboratory in general. As a starting point, let us examine the now traditional explanation of the signal averaging technique.

\section{SIGNAL OR SIGNALS?}

Prior to the introduction of the signal averaging technique to electroencephalography, it was commonly and correctly assumed that EEG potential changes which clearly and characteristically relate to some specific form of sensory stimulation cannot be demonstrated in the normal $S$. In applying the signal averaging technique to the EEG, the investigator usually argued that specific evoked potential changes were not evident in the scalp EEG since they were relatively small and buried in the 
continuous electrical activity of the brain. Signal averaging is viewed as a way of detecting or extracting event related potentials present in the electroencephalogram. In the classic example, the $S$ is presented with a repetitive sensory stimulus and the EEG activity is averaged at a number of specific time points immediately following the stimulus presentation. Potentials which are synchronous with the sensory stimulation are said to cumulate while nonsynchronous biological noise is said to have a mean value of zero.

In practice, the signal averaging technique seems to work out quite well. Average evoked potentials are detected when time locked activity is not evident in the ongoing unaveraged EEG. That is, evoked responses are detected in the presence of what is usually termed an adverse signal to noise ratio. The detected average brain potential is termed a "signal" which is said to be extracted from a sample of signal plus noise (the EEG).

The literature shows that signal averaging can be used to detect or uncover responses to sensory stimulation in most modalities. Typically, the responses are not evident in a visual examination of the unaveraged EEG, but they can be detected using signal averaging even when low level near threshold stimulation is used. Not only can they be detected but, as we shall confirm later in this paper, specific stimulus control can be reliably demonstrated if the proper measurement techniques are used. In addition, average potentials can also be detected from the human scalp EEG when the averaging is time locked to events other than those clearly related to sensory stimulation (a motor movement, for example). It is also possible to demonstrate that several time locked average potentials can be present in a single EEG recording.

Most of these findings can be shown with one study. Average potentials synchronized with cardiac cycle, motor activity, auditory stimulation, and visual stimulation were studied. Preliminary testing was conducted to identify average potentials which, singly, could be reliably detected in the EEG without resort to high intensity stimulation, extensive subject effort, or other artifact producing conditions. The following four experimental conditions were identified: (1) average potentials evoked by a 10 -msec duration white light flash (the circular stimulus subtended a visual angle of $0.8 \mathrm{deg}$ and had a luminance of $204.4 \mathrm{~mL}$ ); (2) average potentials evoked by $10 \mathrm{msec}$ duration auditory clicks (these stimuli were delivered to the $\mathrm{S}$ binaurally through earphones and had a peak intensity of about $65 \mathrm{~dB}$ SPL); (3) average potentials time locked to the cardiac cycle (the EEG averaging was triggered by the R-wave of the EKG); (4) average potentials time locked to pressing a small pushbutton (Grayhill 40-100) with the right index finger (the EEG averaging is triggered by the switch closure which required $50 \mathrm{~g}$ for closure).

The light flashes and auditory clicks were systematically presented to the Ss at known phases of the concomitant cardiac cycie. Figure 2 is a block
Table 2

Terms Related in the Literature to Electroencephalogram Signal-Averaging Data

\begin{tabular}{|c|c|}
\hline ANXIETY & INTENIION TO RESPOND \\
\hline AROLSAL, ACTIVATION AND INTEREST & MANINCFLLNESS \\
\hline CONATION & MOTIVATION \\
\hline WUNDITIONING AND L.EARNINT: & Niviei.TY \\
\hline CONIINGENCY & ORTENTING \\
\hline CORRECTNESS AND INCORRECTNESS & PERSONALITY \\
\hline DECISION-MAKINS & POSITIVE AND NEGATIVE EFFECT \\
\hline DELIRILM & REPRESSIVEMESS \\
\hline UETECTIUS: & SECMENTAL SET \\
\hline DIFFICLLTY OF DISCRIMTNATION & SELECTIVE ATTENTION \\
\hline LISTRACTION & SIGNIFICANCE \\
\hline EKDOGENOUS STIMLII & SLEEP-WAKEFULNESS CHANFE \\
\hline EXCITEMENT & SUGGESTION AND HYPNOSIS \\
\hline EXPECTANCY, SET AND READINESS & SYMBULIC OR SEMANTIC VAIUE \\
\hline HABITUATION & TASK RFLEVANCE \\
\hline HANDEDNESS & ENCERTAINTY， PREDICTABILITY \\
\hline INTELLIGENCE（IQ） & VIGILANCE AND ALERTNESS \\
\hline INTENSITY & VISUAL RECOGNITION \\
\hline
\end{tabular}

diagram of the recording computing stimulating system used for these studies. The S's EKG was amplified and rectified to allow reliable triggering of a Tektronix Type 162 waveform generator by the R-wave. The EKG was recorded from the sternum to minimize potential movement artifacts. The EKG-triggered Type 162 then trissesed two Type 161 pulse generators. One Type 161 controlled the light flash shutter and the other controlled the click presentations. This allowed the $\mathrm{E}$ to control electronically the temporal delay beteen the EKG R-wave and the stimulus presentations.

The click and flash stimuli were programmed at various delays to minimize the effects of cardiac cycle and sensory factors on the average potentials evoked. Half of the presentations were made while the $S$ was pressing the pushbutton. The $S$ was instructed to press the pushbutton on request at a self-paced rate not to exceed one push $/ 2 \mathrm{sec}$, and not to coordinate his presses with either flash or click presentations. Pushbutton switch closure triggered a third Type 161. The two Ss were righthanded adult males in good health. The experiment was repeated three times on different occasions on each $\mathrm{S}$ to assure reliability. Trigger pulses synchronous with the auditory and visual stimuli, the finger presses, the EKG R-wave, as well as EEG activity from one pair of scalp leads were recorded on separate channels of an FM magnetic tape recorder. The EEG recordings were from electrodes placed at $\mathrm{C}_{3}$ (Jasper, 1958 ) and the left mastoid process with a ground electrode attached to the right mastoid process.

Figure 3 is a sample of the polygraph records obtained from the two Ss in this experiment. Visual examination 


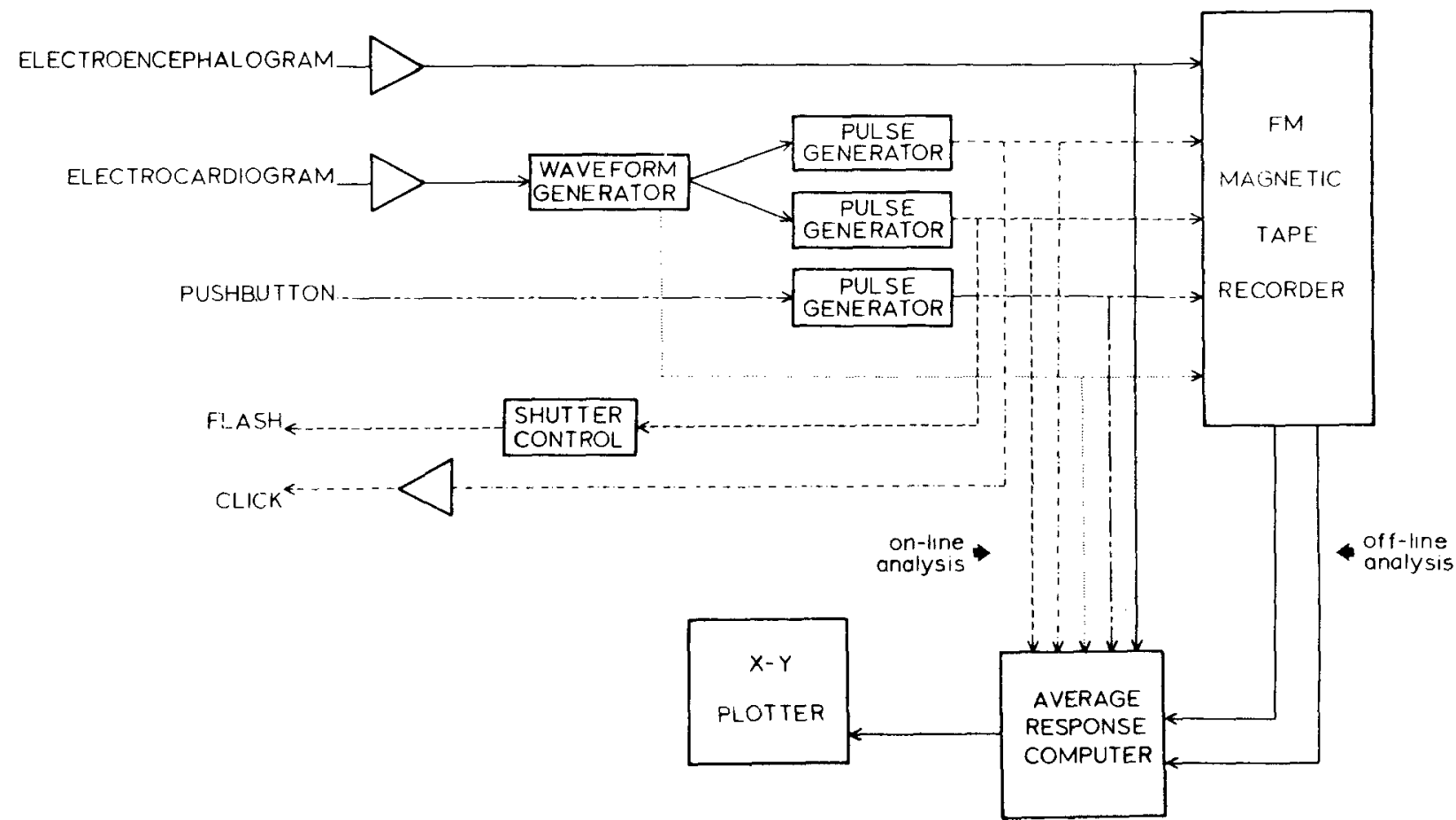

Fig. 2. Block diagram of the recording stimulating computing system used to study concomitant average potentials.



\section{PRESS}

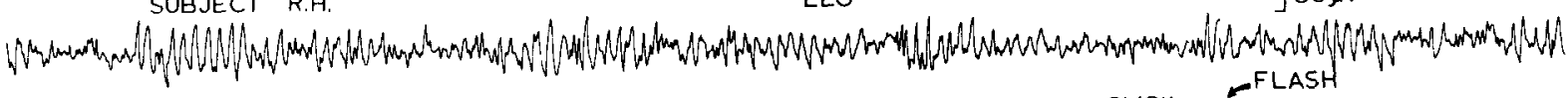
1

Fig. 3. Polygraph recordings obtained from two Ss in the course of sessions which resulted in the concomitant average potentials shown in Fig. 4. One EEG channel and three event marking channels are shown for each $S$.

of the unaveraged EEG records reveals no artifacts or waveform changes clearly associated with any of the trigger pulses recorded. The recordings, however, reliably revealed time locked potentials when subjected to signal averaging. The FM magnetic tape recordings made during the sessions were analyzed off-line by repeated playing, 
forward and backward, into a fixed program digital average response computer (TMC Model 400B).

The average potentials obtained from one experiment for each of the two Ss is shown in Fig. 4. Average potentials synchronous with cardiac cycle, motor activity, auditory stimulation, and visual stimulation were reliably detected and isolated in both Ss for all sessions. The average potentials detected have been aligned with regard to their respective trigger pulses so that a comparison of the various waveforms can be made. The vertical dashed line indicates the trigger pulse time point. Each average potential appears to have a somewhat different form. Within a modality, however, there are similarities. Analysis of the data indicates that these average potentials are not merely harmonics of one or perhaps two fundamental oscillations or average potentials.

The results of these experiments chearly indicate that the signal averaging technique need not be limited to the detection of potentials evoked by direct sensory stimulation. Time locked EEG potentials can be reliably detected which are related to activity other than that evoked directly by sensory stimulation. The changes required for the detection of an averaged potential need not be great. Technically, the problem is one of locating the appropriate trigger pulse and maintaining adequate controls to allow reliable signal averaging.

More importantly, the data also demonstrate that it is possible to detect and measure several average potentials in a single EEG recording using signal averaging. Conventional interpretations of signal averaging may speak of detecting a signal in noise, but the results of this study indicate that we can and have detected several signals in the same noise. Perhaps it is more appropriate to speak of detecting a signal or signals masked or buried by other concomitant signals. In fact, it is tempting to suggest that the EEG is just a mix of very specific time locked signals. One man's signal may be another man's noise.

Thus, the signal averaging technique may provide a very general tool with which one can systematically study not only changes within a given system or mechanism, but also interactions between various systems. This also suggests that the general sensitivity of the signal averaging technique might be significantly improved by monitoring or manipulating the relation of one average potential with respect to time locked activity in the recording. Since we are probably never studying the only signal buried in the noise (the EEG), one might suggest that the simple statistical notions used to communicate the signal averaging technique to potential users was false and misleading. Ordinarily the user assumes that the signal to be detected with signal averaging is to be extracted from an uncorrelated sample of noise having a mean value of zero (Reagan, 1972). Once we introduce the concept of detecting a signal mixed in other signals, one intuitively has a harder time thinking that all of these signals are uncorrelated.
SUBJECT R.O.

SUBJECT R.H

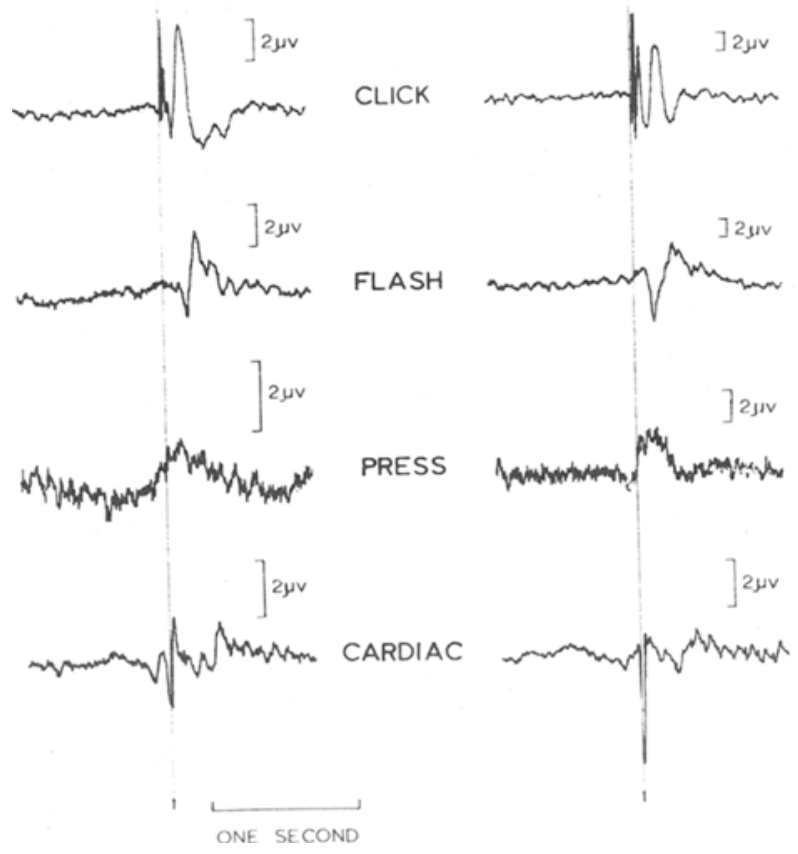

Fig. 4. Concomitant average potentials obtained from one experiment for each of two Ss.

I propose that the signal in noise statistical notion was a good one, even if it was in error. Simple mathematical assumptions are just as important as are simple mathematical operations in encouraging new users of a new methodology. Don't worry about whether you are meeting all of the assumptions when you try a new technique. just try it. If you are adopting a theory to promote the disscmination of a new technique, you will have the greatest evangelistic effect if you use a simple theory. The important thing is not to take the theory too seriously for the time being so that failure to meet the theoretical assumptions stops progress. It would be nice to think that one could start with a fairly accurate measurement model that could easily be tested with good basic research, but it is generally difficult and sometimes impossible. Things are seldom as simple as they initially seem. On the other hand, simple concepts frequently have considerable heuristic value.

The application of signal averaging to human EEG scalp recordings was an ideal case. We were able to accept comfortably a simple model simply because we were trying to measure something we literally could not see or study given conventional methods of analy sis. The technique worked, the simple theory was comfortable, and the theory could not undergo serious challenge until we actually had a feel for what we were measuring. After 15 years, we are finally starting to ask some of the right questions. Fifteen years ago we didn't know the questions that needed answering, although I am confident that many would have told you that they knew. Pick a simple 


\begin{tabular}{|c|c|}
\hline ACF - ASSOCIATION CORTEX POTENTIALS & ERP - EVENT RELATED POTENTIALS \\
\hline AECP - ALDITORY EVOKED CORTI AL POTENTIALS & EVR - EVOKED VERTEX RESPONSE \\
\hline AEP - AVERAIE EVOKED POTENTIAL & MER - MONOCULAR EVOKED RESPONSE \\
\hline AER - AUDITORY EVORED RESPONSE & PEM - POTENTIALS EVQQUES MOYEN \\
\hline AER - AYERACED ELECTROENCEPHALIC RESPONSE & SECP - SOMATOSENSORY EVOKED CORTICAL POTENTIALS \\
\hline AVR - AVERAGE VISUAL RESPONSE & SEP - SOMATIC EVOKED POTENTIAL \\
\hline BER - BINOCLLAR EVOKED RESPONSE & SER - SOMATIC EVOKED RESPONSE \\
\hline CEP - CORTICAL EVOKED POTENTIALS & SER - SOMATOSENSORY EVOKED RESPONSE \\
\hline CEP - COMPOLND EVOKED POTENTIAL & V POTENTIAL - VERTEX POTENTIAL \\
\hline EBR - EVOKED BRAIN RESPONSE & VECP - VISUAL EVOKED CORTICAL UTENTIALS \\
\hline EOP - EVOKED OCCIPITAL POTENTIAL & VEP - VISUAL EVOKED POTENTIAL. \\
\hline LP - EVOKED POTENTIAL & VER - VISUAL EVOKED RESPONSE \\
\hline
\end{tabular}

Table 3. Names used in the literature to describe the waveforms produced by electroencephalogram signal averaging. theoretical position that allows you to work with your new tool in a comfortable way, but ask the right questions once you have found your way around.

\section{STANDARDIZE OR STANDARD WISE?}

The immediate result of signal averaging is, of course, a listing of sum or mean voltages computed for a number of consecutive time points. The number of time points in early applications was as few as one or two. In contemporary research, the number is usually several hundred and may reach a thousand or more. Most modern signal averaging systems perform all computations on digitized data. The sum or average is usually then converted into analog form and displayed on an X-Y plotter or analog scope. The product is an analog waveform, such as those already displayed in this paper, somewhat similar in general appearance to the evoked response waveforms gathered by electrophysiologists for years without the use of signal averaging. Sensory evoked potentials can, of course, be recorded directly if electrodes are placed in brain structures or near peripheral sense organs.

As we have shown in Table 2, signal averaging has been used to study a large number of topics. In a similar and perhaps related manner, investigators have invented a large number of names to describe the waveforms produced by EEG signal averaging. Table 3 is a partial listing of some of the names used to date. The use of acronyms and abbreviations is rampant and perhaps confusing. Inspection of this table reveals, among other things, that in more than one instance the same abbreviation has been used by different authors to communicate different things. The abbreviations AER and CEP are good examples. Other abbreviations appear to represent words that communicate a variety of things: modality stimulated, stimulation method, electrode location, neural origin, average response method, etc.

One is tempted to suggest that investigators or journal editors resolve this problem by adopting or imposing a name(s) for use with the products of EEG signal averaging. At least one effort (Riggs, 1970) has been made, but universal adoption has not resulted to date. I would like to argue against standardization at the present time, taking a conservative position which holds that our knowledge about the phenomena has not as yet progressed to the point where we can express any confidence in a final selection of a name or names that have fairly permanent meaning and significance. Some things can be done, however, to minimize the confusion.

Why do authors use acronyms and abbreviations to refer to EEG signal averaging waveforms? One obvious benefit that must be respected is that it shortens articles. I suspect, however, that authors are not overly concerned with the number of words typed in the text or the page limitations imposed unpon editors by publishers. In attaching a name to their waveforms, authors are telling readers something about their belief concerning the origin or source of the variables they are reporting on. For example, when the term "cortical" is included in the name, the author is saying that the potentials probably originate in the cerebral cortex. When the term "auditory" is used, we are being told that the origin of sensory stimulation is primarily auditory. When "average" is used, we are told something about the technique which served as the source of the data reported.

I have no objection to efforts by authors to emphasize different factors by selecting different names. The important thing is that the author is aware of this option and that he chooses the name that best reflects his current emphasis or bias. Editors should not impose a specific name on all authors, but they should make sure that the author knows what he is implying when he does use a particular name. For example, the author who uses the VECP (visual evoked cortical potential) description should be aware that he is implying to the reader that he believes that the waveforms being reported have a primary source in cerebral cortex. I am convinced that many authors use names adopted from others without giving serious thought to what is implied or assumed by the name they are using. Others may invent new names in a creative spree void of any logical significance or evaluation.

Editors should challenge authors as to the logic and intent behind the name they select. Given our current 
state of knowledge, there are many acceptable names for EEG signal averaged waveforms. Some of the current usage may embarrass authors at a later date, but I do not feel that should be an issue at the moment. I agree with Riggs (1970) in that some names are much too vague and communicate little. EP (evoked potentials, for example, tells the reader little if anything. One does not know if signal averaging is involved, the modality of stimulation, or the author's guess as to neural source. AEP (average evoked potential) tells a little more, but only that signal averaging was used. It is important that authors specify to the reader what they think they are doing or studying. Sometimes this is not clearly evident anywhere in the article. Extended methods and discussion sections can do much of this but are not always tolerated by editors. In many cases the selection of a good name will do the same thing much more easily.

I have used the name EBR (evoked brain response) to describe the EEG signal average waveforms from scalp recordings. In using this, I an: simply communicating my bias that the potentials under study are primarily from the central nervous system (CNS). The specific source(s) in the CNS is not suggested by this description, thereby leaving the issue open to future speculation based on new empirical findings. For the present, I do not feel comfortable assigning a waveform or waveform component recorded from the scalp to a specific neural structure or area. We may be able to do this in the future. If necessary, prefixes can be added to the EBR name to indicate things like modality of stimulation, conditions of stimulation, or method of analysis. The basic EBR name is especially handy when the waveforms under analysis have been evoked by simultaneous stimulation in more than one modality. In any case, I would be the last person to suggest that the EBR format enjoy any sort of universal adoption. For the remaining portions of this paper, I shall refer to the EEG signal averaged waveform computed from human scalp recordings as the EBR.

It is interesting to note that few, if any, investigators have actually incorporated "EEG" into their signal averaged scalp EEG waveform name. Although the subject is open to some debate and has been explored in the literature, I think most investigators in the area assume that the signals they study are not clearly kin to the conventional EEG display. On an intuitive and visual examination basis, this is supported. We like to think that in most cases the signal averaging of the scalp EEG has allowed us to study an entirely new class of CNS phenomena in man. Perhaps this area is a good example of an advance in which the introduction of the computer has uncovered a completely new area of scientific inquiry.

\section{FORMS OR FUNCTIONS?}

Having chosen a name for his average potentials, the EEG signal averager is then faced with an additional
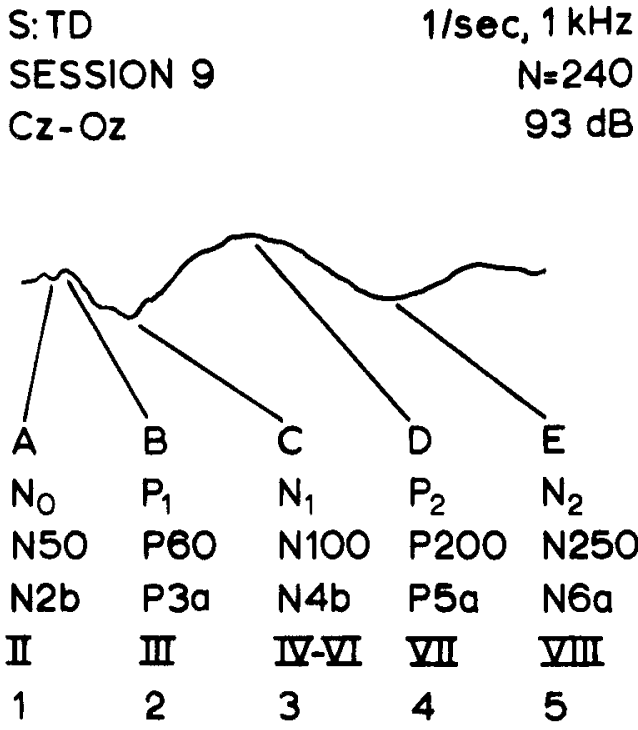

Fig. 5. Auditory evoked brain response recorded from S TD on one trial in Session 9. Data from a study by Tepas, Boxerman, \& Anch (1972). Response deflections are identified using six different nomenclature systems.

decision. What system of nomenclature should he use to identify the dips and peaks of the average waveforms which he detects? Here, again, the investigator has a wide selection. Figure 5 shows an EBR waveform with the dips and peaks identified following the manner of six different nomenclature systems.

In identifying one EBR with six nomenclature systems, I have placed myself in a precarious position of sorts. The historical origin of each nomenclature system is not always clear. In some cases, a given nomenclature is not used in a consistent manner in the literature. I fully expect that some investigators will not agree with the specific identifications I have made in Fig. 5. All of these factors serve to illustrate a major point which should be made. That is, the use of an absolute identification method in the formative period of a new area of research is inappropriate. It assumes that one has a good idea of the number of items in the particular population involved and that you know enough about that population to make appropriate classifications or distinctions. I shall argue that experience to date clearly indicates that absolute identification schemes have been a disappointment due to our naivete.

Rather than present a critical evaluation of specific investigators or studies, I will point out a number of problems inherent in most of these nomenclature systems. A number of studies provide examples of how these nomenclatures have been used (Barnet \& Goodwin, 1965; Ciganek, 1966; Goff, Matsumiya, Allison, \& Goff, 1969; Rapin, Schimmel, Tourk, Krasnegor, \& Pollak, 1966; Vaughan, 1969; and Vaughan \& Ritter, 1970).It would be quite inappropriate to suggest that any of these authors intended to instigate or promote nomenclature confusion. 
The nomenclature system in Fig. 5 which uses only alphabetical characters to identify EBR peaks should be discussed first, perhaps, since it is the one used most frequently in my laboratory. I am convinced that this is the simplest and most appropriate approach, given our present state of knowledge. With this system, the deflections to be measured in a specific study are identified by alphabetical letters in a text illustration. In assigning letters to deflections, only one rule is followed: Letters must be assigned so that alphabetical position is keyed to latency as delimited by the signal averaging analysis time. Thus A must occur before B, B before C, etc. The user does not make an assumption which appears to be made with the other nomenclature systems: Once a label has been assigned to a deflection one assumes that a firm and relatively final absolute assignment has been made. With these other systems, the same term is to be assigned to that deflection whenever it is observed in subsequent research. From a conversational viewpoint, this would appear to be quite nice, but from a practical viewpoint it is an unnecessary limit or restriction which in fact may mislead investigators as often as it assists them.

With the simple alphabetical system as we use it, it is acceptable to use different labels in different studies for what may be the same deflection. The only important thing is that the use be consistent within each study. The alphabetical labels are simply labels to show what was measured in a given study and nothing else. Essential to the approach is the inclusion of calibration, stimulation, and recording location information in the figure and in the text. Given this information, the reader has what is required to compare the measurements reported in the study with those present in other reports, assuming that all reports provide appropriate details. Thus, the reader can judge for himself.

Now let us look at the other terminology approaches. Perhaps one of the earliest and most popular approaches is one using the alphabetical letters $N$ and $P$ in combination with numerical subscripts. The letters are used to indicate the direction of the deflection with $\mathrm{N}$ indicating a negative deflection and $\mathrm{P}$ indicating a positive deflection. This polarity designation is only significant, of course, when made in reference to a particular electrode location. Numerical subscripts are used to indicate order with the two letter categories, $\mathrm{N}$ and $\mathrm{P}$. One obvious problem with this system is shown by the $\mathrm{N}_{0}$ designation in Fig. 5 . Early research on the EBR concluded that the first significant deflection that might be measured reliably was a positive one labeled $P_{1}$. Some later EBR studies concentrated on a previously unstudied negative deflection occurring before $P_{1}$. Rather than renumber the subscripts, the authors chose to add a new one, $\mathrm{N}_{0}$. There are other similar examples in the literature where new subscripts were added rather than simply attempting to label the components observed in a specific study.

In practice, some investigators either ignore previous subscripting or intentionally renumber the deflections. Since many investigators approached the literature with the mental set that the nomenclature was fixed and absolutely linked to specific deflections, discrepancies in results have been perceived and discussed when, in fact, the experiments were not even measuring the same deflections. Out of these complications evolved a terminology keeping the $\mathrm{P}$ and $\mathrm{N}$ polarity designation but substituting general latency values for the simpler numeric subscripts. Thus the designations N50, P60, etc., in Fig. 5. A third nomenclature system using the polarity designation is also shown in Fig. 5 . This system is a further attempt to improve the nomenclature by accommodating for differences in latency related to modality stimulated and electrode placement. With this system, six latency ranges, designated by the numbers 1 to 6 , are used together with a letter suffix which indicates order within categories. Thus, the terminological system becomes more complex as experimentation introduces more exceptions to the basic assumptions involved.

Polarity is very important and this point of information must be included in every research report. I see no reason, however, to include it in the nomenclature itself. Clearly, polarity is dependent upon recording location with reference to the source of the potentials under study. One should not say, however, that the location of the source depends upon the polarity of the recording. Literally, source determines polarity of recording, but the recordings cause nothing.

The polarity of a deflection can vary with different scalp locations. For example, Vaughan (1969) has reported that the $\mathrm{P} 200$ response to auditory stimulation is negative for some scalp recording locations in man. Similarly, the polarity of a scalp deflection does not correlate with intracranial polarity in a simple positive manner. There is evidence that human scalp EBRs have a polarity and shape similar to epidural cortical surface responses (Domino, Matsuoka, Waltz, \& Cooper, 1964). However, animal studies comparing surface cortex with simultaneously recorded potentials at various depths in the cortex show that the response to auditory stimulation reverses polarity in the cortex for some components (Hall \& Borbely, 1970). The study of polarity changes as a function of electrode location is an important technique for the identification of the sources of EBR deflections. A nomenclature that uses polarity designations can easily obscure significant polarity reversals. At the very least, discussions using $P$ and $N$ nomenclature become quite complex and confusing when recording location is varied.

The remaining two terminological approaches use Roman or Arabic numerals to identify deflections. At first glance, these approaches appear to be quite similar to the alphabetical system I have proposed. They differ to the degree that authors use them in a firm, fixed manner that strives for consensus from study to study and does not promote renumbering of deflections. Thus, 
Deflection C is labeled IV-VI in Fig. 5 rather than IV or III. Given different conditions, studies have shown three distinct deflections in this area. While three deflections may be present in this recording, they would certainly be difficult to measure or distinguish in an independent manner. Faced with such issues, users of the Roman numeral nomenclature would not label $C$ as Deflection IV or D as Deflection V, for example. Again, there seems to be a sacred trust which states that the originator of the terminology is able to foresee all possible deflections and their relative significance. I find that difficult to accept.

Perhaps the advantage of our flexible alphabetical system can best be seen in two examples from studies completed in our laboratory. In the top half of Fig. 6, an EBR waveform to paired auditory and visual stimuli is shown (Tepas \& Klingaman, 1971). In this experiment, light flashes were presented to the $S$ at a $1 / \mathrm{sec}$ rate. One-kHz tonebursts followed the flash onset by $267 \mathrm{msec}$. The flash had a duration of $31.5 \mathrm{msec}$ and the burst a $30-\mathrm{msec}$ duration. The resulting waveform shows prominent deflections following both the visual and auditory stimulus. Following the rules of the alphabetical system, the deflections we wished to measure are labeled consecutively A through $\mathrm{H}$. Labeling this waveform using a terminology that is not flexible and does not permit renumbering can be done easily, of course, by regarding the flash and burst responses as independent and noninteractive entities. In fact, they are not and I see no reason to ignore this. What is not clear is whether the interaction is a neural one or simply the algebraic addition of the two EBR waveforms via volume conduction. One could also regard them as interacting entities deserving unique labels to be used only in paired stimuli experiments using visual-auditory stimulation. From my viewpoint, it is ridiculous to adopt either strategy since both require that you make some strategic assumptions about unknowns.

The lower half of Fig. 6 shows EBR waveforms to the onset and cessation of long duration auditory stimuli (Klingenberg, 1973). In this experiment, $1-\mathrm{kHz}$ tones with a duration of $2000 \mathrm{msec}$ were presented once every 4 sec. Following the rules of the alphabetical system, the deflections measured were labeled consecutively A through I. Thus, the letter $G$ marks a deflection following the cessation of a long duration auditory stimulus. In our paired stimuli study mentioned above, the letter $G$ was used to mark a deflection following the onset of an auditory stimulus. In both of these experiments, the letter E marks a deflection following the onset of the auditory stimulation, but examination of Fig. 6 indicates that comparable deflections are not being measured in each case. In a third study in our laboratory, the letter $\mathrm{E}$ has been used to designate a deflection following the cessation of a long duration visual stimulus (Dinges, 1973).

For some, the flexible and reorderable alphabetical labeling system demonstrated in the preceding
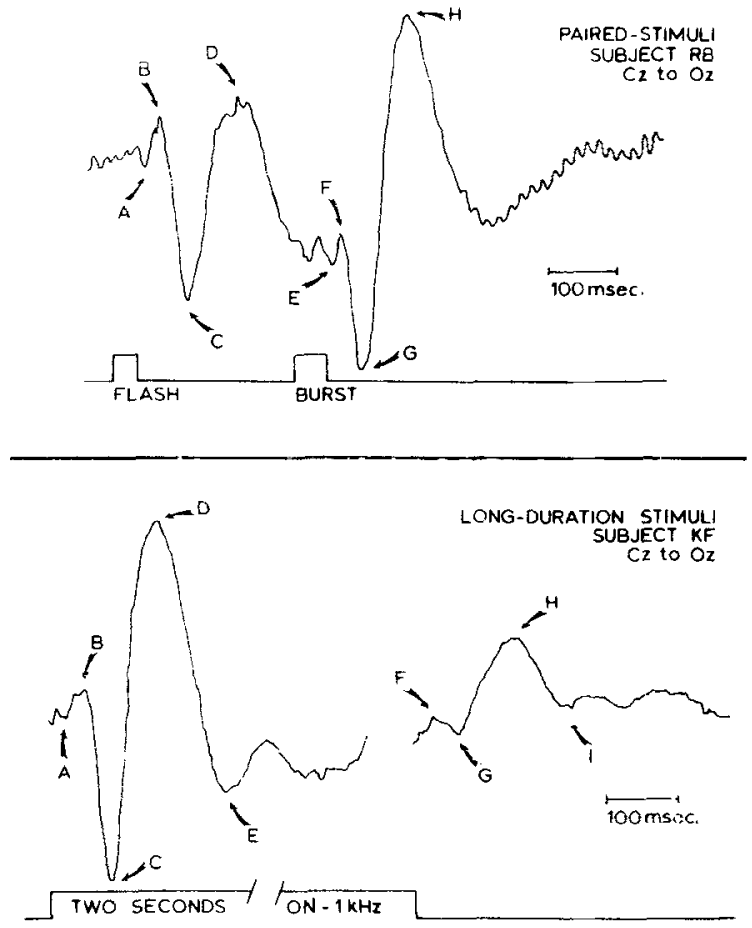

Fig. 6. Use of the alphabetical nomenclature system. The upper portion of the figure shows the evoked brain response waveform to paired auditory and visual stimuli from a study by Tepas \& Klingaman (1971). The lower portion of the figure shows the waveform to the onset and cessation of a long duration auditory stimulus from a study by Klingenberg (1973).

paragraphs may be unacceptable and intolerable since it does not clearly identify deflections with direct reference to labels previously touted in the literature. As I see it, this is not a problem but rather an advantage, if the methods section is detailed and the reader is reasonably intelligent. Comparison of results with the findings of previous research belongs in the discussion section of a research report, not in the methods or results sections!

Frequently one observes reports in the physiological literature in which the authors present displays of waveforms as the final data analysis. No measurements are made (or at least reported) other than the signal averages themselves. Examining waveforms in this manner is a dangerous exercise. I apologize for those occasions when I have already asked you to do just that in this paper. It is a seductively easy thing to offer. In general, the simple judgment of waveforms is quite like the activity of most clinical electroencephalographers, which may explain its popularity. The usual application of conventional EEG recordings by the clinical physician involves the somewhat casual examination of several yards of polygraph data. Such an approach has not helped improve the reliability of conventional EEG data (Blum, 1954), and I personally doubt its value for EBR research. It would seem somewhat ridiculous to me if EBR research led in the application of computer techniques to the life sciences, and at the same time it 


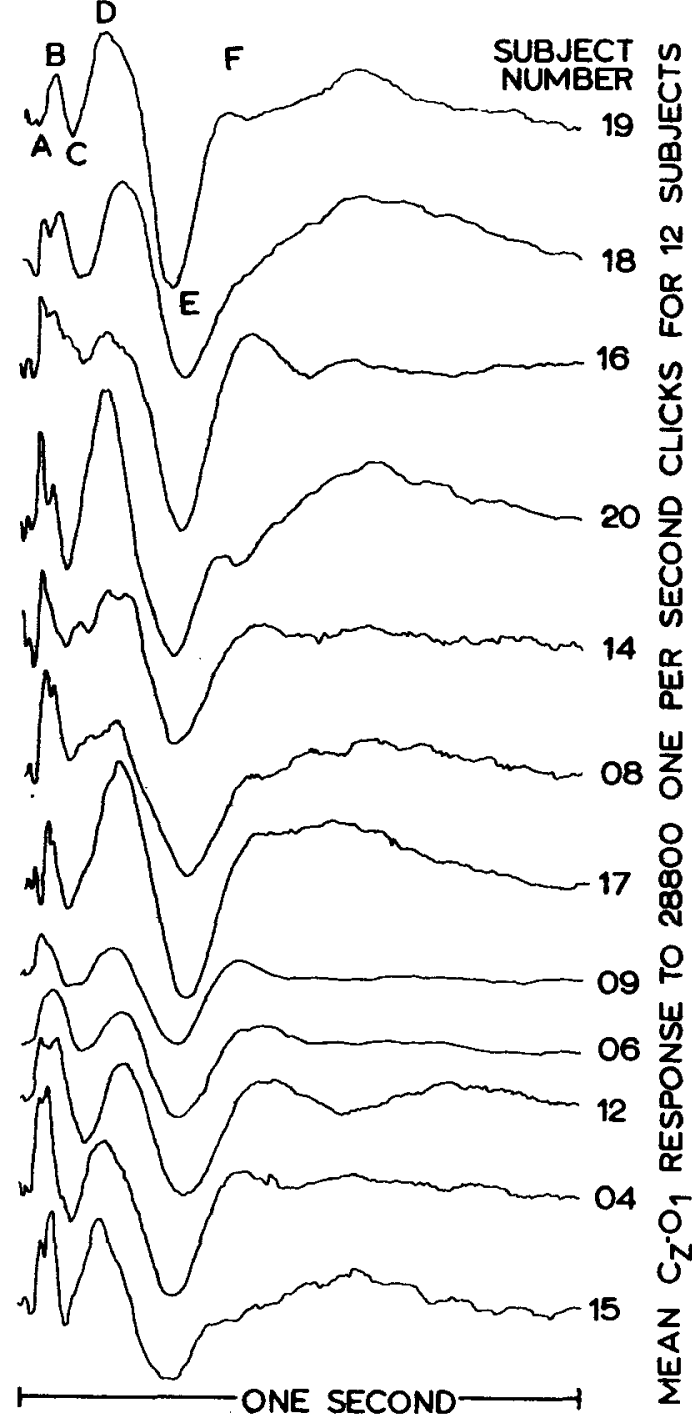

Fig. 7. Auditory evoked brain responses from 12 Ss. Each waveform produced by EEG signal averaging to 28,800 clicks presented over a 48-h period. Data from a study by Tepas (1967).

ended up with a subjective evaluation of waveforms as its final product. EBRs are to measure, not watch.

If EBR waveforms are the final data display, then perhaps the selection of deflection labels is very important. After all, it is an attempt by the author to evaluate his results in light of the known literature. With this approach, using labels in a sacred but unwieldy manner becomes an important exercise since it is also a major path for the communication of results to the reader. If, on the other hand, you do not view a waveform as the ultimate product of the current technological age, waveform labels are only codes attached to measures to make later data management easier. It is this approach which I prefer to promote.

I have made an effort in the course of this paper to speak of waveform deflections, dips, and peaks rather than of components or processes. To me the terms component and process are hypothetical concepts generated by parametric research aimed at uncovering functional relationships. The endpoint of EBR research should be improved component or process knowledge, not more information about waveform deflections. In the final analysis, EBR measurement points may not match perfectly component or process findings. The R-C circuit characteristics of most ac EEG amplifiers probably assures this. EEG research should be aimed toward the demonstration of wave functions rather than wave forms.

In discussing a name for the product of EEG signal averaging earlier, I suggested that this matters little since the major purpose was to communicate what vou thought you were measuring. Your choice may enlarge or restrict your audience, but I doubt that it will significantly influence your research strategy in any seriously restrictive sense. On the other hand, in choosing a terminology for waveform deflections, you may very well be making some very important decisions. If you select and maintain a very restrictive and inflexible methodology, you are probably structuring the range of problems available for study, your methods of analysis, and your ability to evaluate the results. A flexible labeling method which is open to additions, change, or dismissal is your best bet. It cannot embarrass you with data or experiments which you cannot describe using your normal nomenclature format. It cannot lead you to conduct experiments simply aimed at supporting a "holy" labeling system.

EEG computer analysis has been and is a challenge in that it has led researchers into fairly unexplored areas to look at things about which little is known. One can measure and describe functions that have never been studied before. I assume that comparable developments are now occurring and will occur in many areas of psychology with the more widespread application of computer technology. Do explore the unknown, but in so doing, do not willingly select or adopt terminology that may limit your explorations and/or confine your functions only to concepts of the past.

\section{VARIABLE OR INVARIABLE}

I have stressed the importance of studying EBR functions rather than waveforms per se. Some investigators have suggested that EBR measures are subject to considerable variability (Buchsbaum 1971). One might conclude that any effort to relate EBR measures to physiological or psychological processes in a fairly straightforward manner is difficult or perhaps even inappropriate due to excessive variability. Data collected in my laboratory in the last 3 or 4 years appears to contradict this suggestion. I believe the issue can be clearly resolved if we look at the methodology and data related to our studies.

A significant change in strategy governing my EBR research resulted from some peripheral findings 
Fig. 8. Block diagram of the stimulating recording analysis system used to study auditory and visual evoked brain response intensity functions.

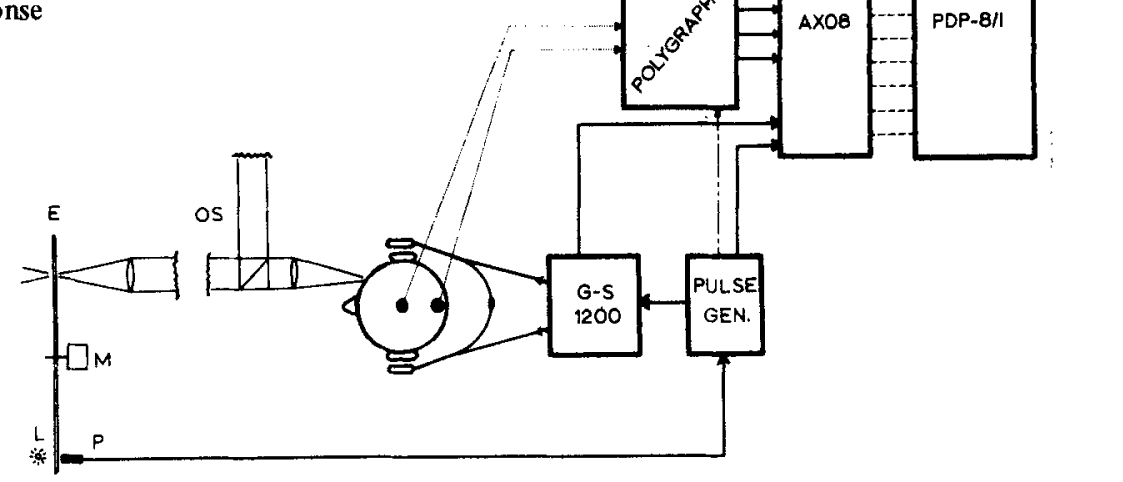

associated with a study that I directed several years ago in which EBR measures were recorded from men confined to an experimental chamber for 48 -h periods (Tepas, 1964). Figure 7 shows EBR waveforms computed for $12 \mathrm{Ss}$. Each of these waveforms is the sum of 28,800 EEG potentials following click stimulation. As these responses were collected, the Ss were involved in a variety of activities: eating, sleeping, defecating, exercising, etc. Many of these activities produce excessive artifactual noise of biological, mechanical, and electrical sorts. The potentials were not recorded on a standard polygraph and were not subject to severe filtering. Examples of EBRs collected in this study when the waveform was only the sum of 200 presentations have already been reported (Tepas, 1967). Many of them are noisy and artifact ridden. What impressed me was the fact that the very large sample EBR waveforms, as shown in Fig. 7, were relatively clean, artifact free, and all showed the same major components to a reasonable degree.

As a result of this finding, I concluded that much of the variability present in EBR data had its origin in the use of small samples and perhaps relatively poor experimental control. Thus, most subsequent experimentation conducted under my direction has involved the use of relatively large samples and refined experimental controls. This appears to have paid off to the extent that we now have six or so parametric studies all showing a significant improvement in stimulus control of the EBR. In one of these studies we have been able to demonstrate that EBR variability is not correlated with EEG variability or with stimulus parameters under the conditions studied (Tepas, Guiteras, \& Klingaman, 1974). This suggests that EBR research must consider the importance of sample size (N) not only with regard to how many stimuli must be administered to reasonably separate the signal (the EBR) from the EEG, but also how many EBRs must be computed to obtain a reasonable estimate of true EBR values. These questions have not as yet been answered in the laboratory, but a review of our methodology and an examination of some of our data may provide some useful hints as to the appropriate methodological controls and sample sizes.

Figure 8 provides a block diagram of the stimulating, recording, and analysis system used. The computer is a 4K PDP/8-I LAB-8 averaging system equipped with Option XR. It is interfaced with a Grass Model 7 polygraph, a two-channel Maxwellian view optical system (QS), a binaural stimulation system (G-S 1200), a Teletype unit (ASR33), a cathode ray oscilloscope display (CRO), an X-Y plotter, a high speed paper tape punch and read unit, and a Tektronix pulse generator. In an early version of the system, a photocell $(\mathrm{P})$ in the optical system triggered the pulse generator which signals the computer to provide synchronization of averaging with flash presentations. In its present version, a computer stepper motor has replaced the episcotister (E) in the optical system and it is driven by a control unit which responds to pulses from the auditory stimulation system.

The auditory stimulation system has been previously diagrammed in the literature (Tepas, Boxerman, \& Anch, 1972). It consists of two completely separate channels of Grason-Stadler Series 1200 psychoacoustic modules that deliver monaural or binaural tone bursts to matched TDH-39 earphones. Tektronix pulse generators and Grason-Stadler timers allow the E to control not only the characteristics of stimuli delivered to each ear but also the relationship of these stimuli to visual stimulation. Thus the system is capable of both combined visual-auditory stimulation, auditory 


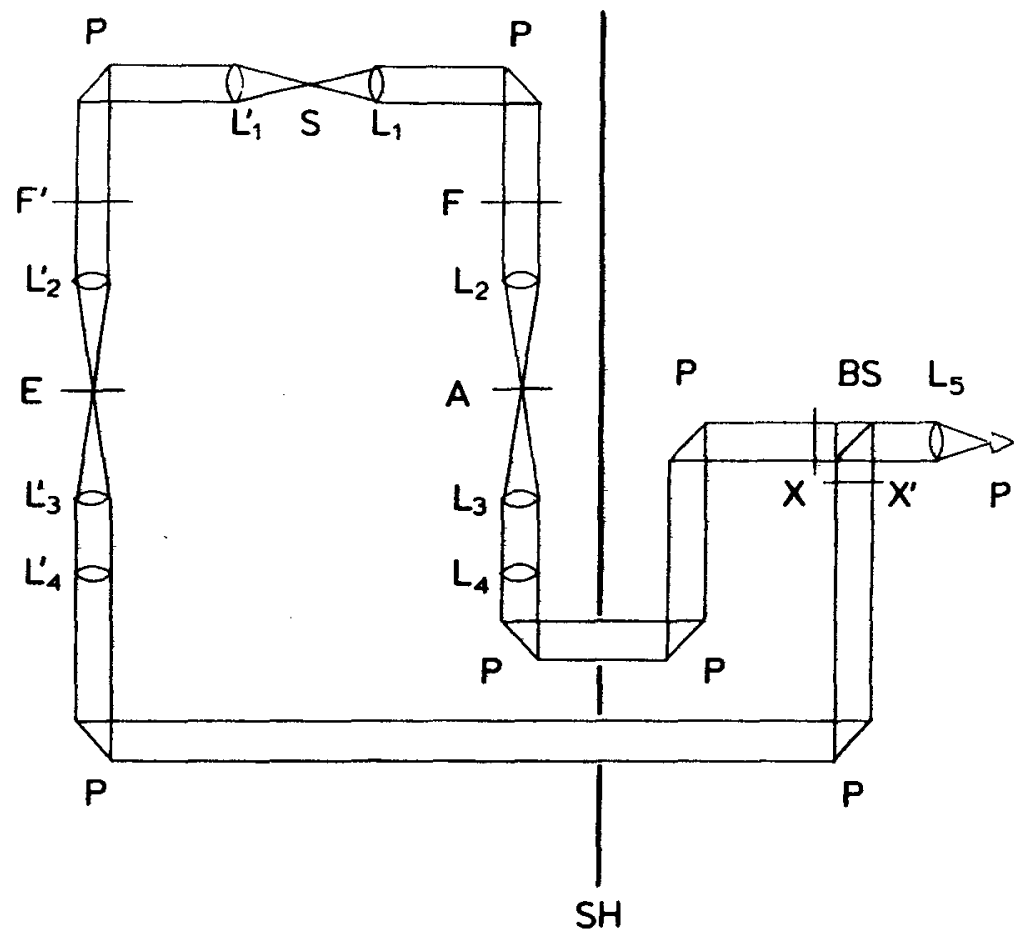

Fig. 9. The two channel Maxwellian view visual stimulation system.

TWO-CHANNEL MAXWELLIAN-VIEW SYSTEM

stimulation alone, or of visual stimulation alone.

Figure 9 is a diagram of the Maxwellian view stimulation system in its present configuration. This system uses light supplied from a tungsten ribbon filament lamp (S), with one lamp supplying both channels. Current is maintained from a storage battery at $18 \mathrm{~A}$ by adjusting the voltage drop across the filament. Appropriate prisms (P), lenses (L), and a beam splitter (BS) permit focusing of both light beams in the plane of the S's pupil (P). Apertures are located at (A) and (E). Either the episcotister or the stepper motor shutter at aperture (E) controls flash rate and duration. Fixed value neutral density filters can be inserted in either field to vary luminance. Apertures at $X$ and $X^{\prime}$ control the size and shape of the two light channels. Ss are assisted in maintaining their proper Maxwellian view at $P$ by a rigidly mounted yet adjustable biting board bearing their wax dental impression. The system is constructed so that all filters, the lamp, and the controlling motors are located outside of the shielded subject recording room wall (SH). For a detailed discussion of the Maxwellian vew, see Westheimer (1966).

The digital values associated with each average response waveform are placed on punch paper tape via the high speed punch at the completion of averaging. Once an experiment is completed, EBR data on tape are merged by high speed reentry of tapes into memory and additive or subtractive merger with other similar data. Finally, merged data are plotted on the X-Y plotter, punched out via the high speed punch and printed out in digital values on the teletypewriter. EBR measurements are normally made from the digital values typed for the merged waveforms.
All of the above are intended to increase the precision of both stimulus presentation and data analysis. Additional methodology strategies include: the repeated testing of trained subjects; the use of relatively large Ns; randomization of the order of stimulus presentations; control for dark adaptation effects; standardized intertrial intervals; use of moderate stimulus levels; testing of all experimental conditions within each session; screening of Ss for sensory acuity or threshold deficits; and control for possible time of day factors. Research is needed to evaluate the degree to which each of these strategies actually minimizes overall variance. In the meantime, the value of the overall approach must mainly rest on the success of the overall approach.

Figure 10 is an example of the results obtained with these efforts. For this experiment the stimuli were white light flashes presented at a $1 / \mathrm{sec}$ rate with a $31.5-\mathrm{msec}$ duration and a $3.3-\mathrm{msec}$ rise-fall time. The flashing foveal target subtended a visual angle of $1.5 \mathrm{deg}$ and had a constant luminance 17-deg surround field with peak transmissions at $400 \mathrm{~nm}$. Each of the points in the figure is the average of 10 sessions with 200 stimuli administered at each session. Thus, each luminance level has an EBR amplitude value which is the sum EEG signal average for 2,000 stimulus presentations. The EBR amplitude-intensity function in Fig. 10 represents the data for one $S$ with a function fit to the data by least-squares computation. The correlation coefficient of +.925 is reasonably representative of what is obtained in our studies. Correlation coefficients for appropriate measures commonly range between .85 and .95 .

In using the linear regression technique, we are not assuming that the EBR amplitude luminance function 
for all levels of stimulation is best fit by a straight line. Additional data with stimulation at higher or lower luminance values may very well reveal a nonlinear overall amplitude luminance function. What we have clearly shown is that EBR variability is not at all so variable as to prohibit efforts to determine EBR functional relationships. Among other things, the results do confirm the suggestion that variability is less when sample $\mathrm{N}$ is increased. The definitive study of the importance of sample size remains to be done, but we can get some further insight and support by reconsidering some of our evidence to date. We might ask, reconsidering the data presented in Fig. 10, how shall we even state the size of the sample? Most EBR reports would list the sample size as $\mathrm{N}=2000$. That may be the appropriate number to use when considering the EEG signal to noise reduction sample, but we might also list the sample size as $N=10$, since this is the number of EBR samples actually extracted. Since EBR and EEG variance do not appear to be correlated, it is proper to suggest that appropriate sampling must consider $\mathrm{N}$ from both of these perspectives. An $\mathrm{N}$ of 2000 is usually considered a fairly large $\mathrm{N}$, but can we consider an $\mathrm{N}$ of 10 as any thing extraordinary?

Figure 11 is a reexamination of some of the data collected in a previously reported auditory EBR study (Tepas, Boxerman, \& Anch, 1972). Rather than merely looking at amplitude intensity functions fit to data pooled across 10 sessions, regression lines were fit to the data from each of five selected sessions. Only one of the five correlation coefficients computed for individual session data (EEG N $=240$, EBR $\mathrm{N}=1$ ) is statistically significant. The upper graph in Fig. 11 is the result for Session 5. The correlation coefficient of .386 does not even approach significance. This is the median of the five

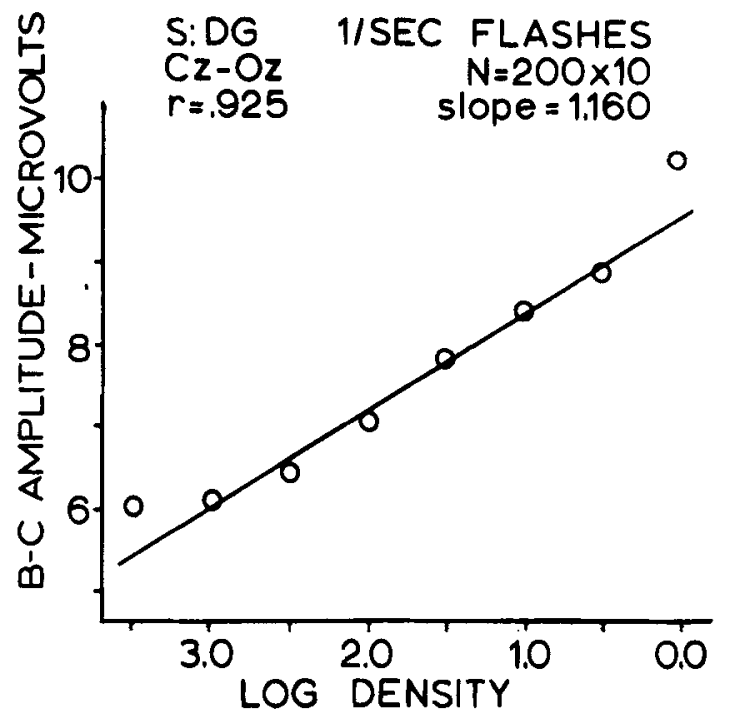

Fig. 10. Visual evoked brain response amplitude intensity function for S DG. The regression line shown was fit to the mean data points using the method of least squares. Data from Tepas, Guiteras, \& Klingaman (1974).

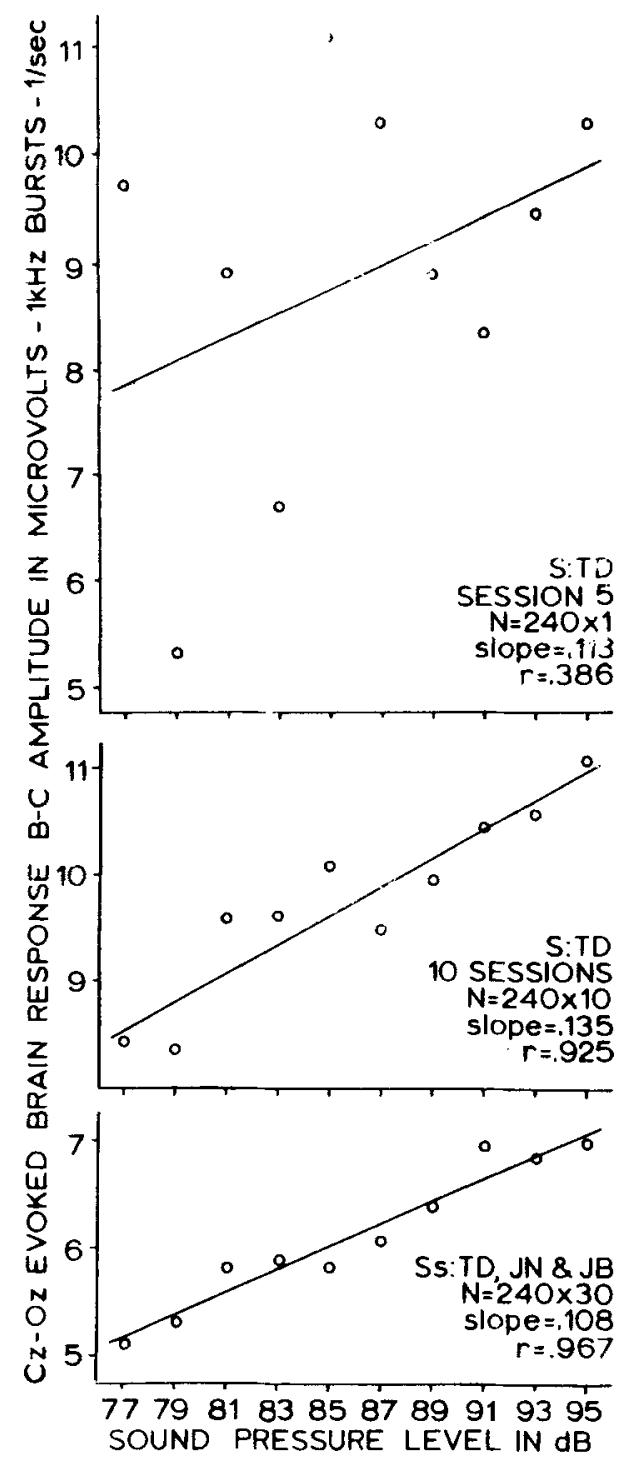

Fig. 11. Auditory evoked brain response amplitude intensity functions. The top graph shows the results from one session for $S$ TD. The middle graph shows the results from 10 sessions for $S$ TD. The bottom graph shows the results for 10 sessions for each of the three Ss pooled, including S TD. All three regression lines were fit using the method of least squares. Data from a study by Tepas, Boxerman, \& Anch (1972).

single-session correlation coefficients computed. All five of the coefficients were positive. As seen in the middle graph in Fig. 11, the correlation coefficient increases to .925 when the data from 10 sessions for S TD are pooled. A further increase to .967 resulted when the data from three Ss were pooled, as is shown in the bottom graph in Fig. 11.

This is not a definitive study, of course, but I feel it does provide a good example to support the notion that normal concepts of what constitutes an adequate sample are probably not adequate themselves. One must consider not only how many EEG samples have been taken, but also how many EBR samples have been collected. I suspect that most investigators reporting 
variable EBR data concentrate on EEG sample size to judge the adequacy of their samples. Given the mental set that samples of 10 or 20 are frequently adequate and that anything over that is very conservative, there is a great discrepancy between the sample size required for an accurate assessment of the EBR and the number assumed to be adequate by the investigator. One would be closer to the appropriate sample size if one maintained the same set as to what constitutes an adequate sample but chose to apply this standard to the number of EBR samples rather than to the number of EEG samples required.

Our results would seem to suggest that there are no shortcuts in collecting data with a computer. Just because you are able to gather data at a higher rate, you must not conclude that the computer provides a quicker and more accurate solution to conventional traditional problems. I suspect that the reverse is true in most cases. That is, the scale of data collection must increase to match the requirements of the new measurements being made. Users of electronic data processing techniques are often accused of gathering too much data. It is usually assumed that they are acting like empire builders, when we might better term them data builders. It is frequently assumed that such users are more interested in data collection than functional analysis. I suggest that in many cases users must be data builders since the adequate or appropriate application of their techniques demands large samples of data. This is a problem which the small scale nonautomated experimenter cannot easily absorb. For years he has been refining and selecting his techniques so that he might complete his experiments without the need for large scale data collection. Large data bases may be required in addition to the tightly controlled experimental conditions which are mandatory.

\section{REFERENCES}

Barnet, A. B., \& Goodwin, R. S. Averaged evoked electroencephalic responses to clicks in the human newborn. Electroencephalography \& Neurophysiology, 1965, 18, 441-450.

Blum, R. H. A note on the reliability of electroencephalic judgm ents. Neurology, 1954, 4, 143.

Buchsbaum, M. Neural events and psychophysical law. Science, $1971,172,502$.

Ciganek, L. A comparative study of visual and auditory EEG responses in man. Electroencephalography \& Neurophysiology, 1966, 18, 625-629.

Clark, D. L., Butler, R. A., \& Rosner, B. S. Are evoked responses necessary? A reply to Donchin \& Sutton. Communications in Behavioral Biology, 1970, 5, Part A.

Cobb, W. A. On the form and latency of the human cortical response to illumination of the retina. Electroencephalography \& Clinical Neurology, 1954 $6,65-84$.
Dawson, G. D. A summation technique for the detection of small evoked potentials. Electroencephalography \& Clinical Neurophysiology, 1954, 6, 65-84.

Dinges, D. F. Human visual evoked cortical potentials to stimulus onset and offset. Unpublished masters thesis, St. Louis University, St. Louis, Missouri, 1973.

Domino, E. F., Matsuoka, S., Walz, J., \& Cooper, I. Simultaneous recordings of scalp and epidural somatosensory evoked responses in man. Science, 1964, 145, 1199-1200.

Donchin, E., \& Sutton, S. The "psychological significance" of evoked responses: A comment on Clark. Butler \& Rosner. Communications in Behavioral Biology, 1970, 5, Part A, 1-5.

Goff, W. R., Matsumiya, Y., Allison, T., \& Goff, G. D. Cross-modality comparisons of average evoked potentials. In E. Donchin \& D. B. Lindsley (Eds.), Average evoked potentials. Washington, D.C.: NASA, SP-191, 1969.

Grass, A. M. \& Gibbs, F. A. A Fourier transform of the electroencephalogram. Journal of Neurophysiology, 1938, 1 , 521-526.

Hall, R. D., \& Borbely, A. A. Acoustically evoked potentials in the rat during sleep and waking. Experimental Brain Research, $1970,11,93-110$.

Jasper, H. H. The ten twenty electrode system of the international federation. Electroencephalography \& Cinical Neurophysiology, 1958, 10, 371-375.

Klingenberg, P. A. Intensity effects of the auditory evoked brain response to stimulus onset and cessation. Unpublished masters thesis, St. Louis University, 1973.

Massachusetts Institute of Technology Communications Biophysics Group. Processing neuroelectric data. Cambridge, Massachusetts: Technology Press, 1959 (M.I.T. Research Laboratory of Eleztronics Technical Report 351).

Rapin, I. Schimmel, H., Tourk, L. M., Krasnegor, N. A., \& Pollak, C. Evoked responses to clicks and tones of varying intensity in waking adults. Electroencephalography \& Neurophy siology, 1966, 21, 335-344.

Reagan, D. Evoked potentials in psychology, sensory physiology and clinical medicine. New York: Wiley-Interscience, 1972.

Riggs, L. A. Review of N. S. Perry, Jr., \& D. G. Childers, The human visual evoked response: Method and theory. Journal of the Optical Society of America, 1970, 60, 1701-1702.

Sutton, S. The specification of psychological variables in an average evoked potential experiment. In E. Donchin \& D. B Lindsley (Eds.), Average evoked potentials, Washington: NASA, SP-191, 1969.

Tepas, D. I. Some relationships between behavioral and physiological measures during a 48-hour period of harassment. Proceedings of the First Symposium on Psychological Effects of Non-Nuclear Weapons, 1964, 1, 112-129.

Tepas, D. I. Evoked brain response as a measure of human sleep and wakefulness. Aerospace Medicine, 1967, 38, 148-153.

Tepas, D. I., Boxerman, L. A., \& Anch, A. M. Auditory evoked brain responses: Intensity functions from bipolar human scalp recordings. Perception \& Psychophysics, 1972, 11, 21 7-221.

Tepas, D. I., Guiteras, V. L., \& Klingaman, R. L. Variability of the human average evoked brain response to visual stimulation, A warning. Electroencephalography \& Neurophysiology, 1974, 36, 533-537.

Tepas, D. I., \& Klingaman, R. L. Interaction of auditory and visual evoked brain responses. Paper presented at the meeting of the Eastern Psychological Association, New York, 1971.

Uttal, W. R. Do compound evoked potentials reflect psychological codes? Psychological Bulletin, 1965, 64, 377-392.

Uttal, W. R. Evoked brain potentials: Signs or codes? Prospectives in Biology \& Medicine, 1967, 10,627-639.

Vaughan, H. G., Jr. The relationship of brain activity to scalp recording of event-related potentials. In $E$. Donchin \& $D$. B. Lindsley (Eds.), Average evoked potentials, Washington: NASA, SP-191, 1969.

Vaughan, H. G., Jr., \& Ritter, W. The sources of auditory evoked responses recorded from the human scalp. Electroencephalography \& Clinical Neurophysiology, 1970, 28, 360-367.

Walter, W. G., \& Shipton, H. W. A new toposcopic display system. Electroencephalography \& Clinical Neurophysiology, $1951,3,281-292$.

Westheimer, G. The Maxwellian view. Vision Research, 1966, 6 , 669-682. 